\title{
Política y religión: martirio jesuita y simbolización monárquica de las Marianas
}

\author{
Politics and Religion: Jesuit Martyrdom and Monarchical \\ Symbolization of the Marianas \\ Fernando Ciaramitaro / fernando.ciaramitaro@uacm.edu.mx \\ https://orcid.org/0000-0002-0299-7057 \\ Universidad Autónoma de la Ciudad de México, México
}

\begin{abstract}
In 1690, an allegorical image of Joseph Mulder published in Seville exalts Queen Mariana of Austria as a protector of Christianity in Mariana Islands. In the Pacific archipelago, the Society of Jesus, supported directly by the ex-regent, and in parallel with the difficult pacification of the territory, carried out an arduous work of evangelization of the indigenous people in which, from the imperial Catholic perspectives, the continuous martyrdoms unfold ideologically as titles of legitimation. Through an iconographic repertoire, it is emphasized how the ideological tonic of torture in the Marianas is not an exception in the apostolic panorama of the Indies, because an evident interference of the religious branch in the political management of the occupation is revealed. However, the missionary intervention is extremely weak in the modalities of penetration of the Catholic message and in the relationship between the preachers and the evangelized.

Key words: Mariana Islands, Jesuits, Mariana of Austria, Martyr Symbolization, Conquest.

Resumen: En 1690 se publicó en Sevilla una estampa alegórica de Joseph Mulder que exalta a la reina Mariana de Austria como protectora de la cristiandad en las islas Marianas. En el archipiélago pacífico, la Compañía de Jesús, apoyada directamente por la exregente, y en paralelo a la difícil pacificación del territorio, llevaba a cabo una ardua labor de evangelización de los indígenas, en la que, desde las perspectivas católicas imperiales, los continuos martirios se desdoblan ideológicamente como títulos de legitimación. A través de un repertorio iconográfico, se subraya cómo la tónica ideológica del suplicio en las Marianas no constituye una excepción en el panorama apostólico de las Indias, porque se revela una interferencia evidente del brazo religioso en la gestión política de la ocupación; sin embargo, la intervención misional se constata enormemente débil en las modalidades de penetración del mensaje católico y en la relación entre los predicadores y los evangelizados.
\end{abstract}

Palabras clave: Islas Marianas, jesuitas, Mariana de Austria, simbolización martirial, conquista. 


\section{Introducción $^{1}$}

A partir de la década de 1990, investigadores, editores y centros académicos han empezado a interesarse más cabalmente en las islas Marianas. Se han multiplicado los impresos relacionados con aspectos diferentes de la vida y la sociabilidad del archipiélago: la geografía y el medioambiente, el turismo, la antropología y los flujos migratorios. Asimismo, se han publicado sugerentes estudios lingüísticos y económicos, sociológicos y de las relaciones internacionales.

Gracias al imprescindible aporte de los departamentos locales de investigación, los historiadores modernistas no han sido exentos de ese recuperado valor; se han concretado pesquisas que abarcan diferentes facetas de la historia de las islas, desde las primeras fases de la conquista, colonización y rebeldía autóctona, hasta los momentos sucesivos de "control" social de los siglos XVIII y XIX. Conjuntamente, los documentalistas, entre ellos Marjorie G. Driver y Omaira Brunal-Perry, han logrado rescatar y dar unidad a fuentes heterogéneas que estaban antes repartidas en numerosos repositorios entre los archivos regionales y, sobre todo, los de Estados Unidos, México, España e Italia. Se ha sistematizado la información documentaria y archivística, se han reeditado informes y memorias de religiosos, viajeros y oficiales de la monarquía española y se han redactado algunos índices de fuentes, utilísimos para las indagaciones correlacionadas. Tales afirmaciones se atinan en las numerosas y recientes publicaciones en inglés y castellano, y en el despertado interés sobre el susodicho archipiélago pacífico (Driver, 1993, 2000, 2005; Driver y Brunal-Perry, 1996; Brunal-Perry, 1997; Coomans, 1997; Ibáñez del Carmen, 1998; Barratt, 2003).

Gracias a un reportorio iconográfico determinado, unas hagiografías, una documentación coeva y una bibliografía especializada, el objetivo del artículo es estudiar, después de hacer hincapié en la historia de la ocupación, colonización y cristianización de las Marianas, la imaginería alegórico-religiosa jesuítica y de la reina Mariana de Austria, exregente y madre del rey Carlos II, como "protectora de la cristiandad de las islas".

1 Este artículo encuentra su íncipit en una corta ponencia presentada en el congreso internacional "El Pacífico, 1513-2013. De la Mar del Sur a la construcción de un nuevo escenario oceánico" (Sevilla, 23-27 de septiembre de 2013), organizado por la Universidad de Sevilla, la Escuela de Estudios Hispanoamericanos y el Archivo General de Indias. Dedico el texto a la memoria de mi añorado maestro José Luis Souto. Tengo, asimismo, que agradecer a Alexandre Coello de la Rosa, Giovanna Fiume y Bernd Hausberger, pues sus lecturas del borrador y sus consejos han sido valiosos para su mejora. 
En el archipiélago la Compañía, apoyada directamente por ella, y en paralelo a la difícil "pacificación" del territorio, punto clave de comunicación entre Filipinas y Nueva España, lleva a cabo una ardua labor de evangelización de los indígenas en la que, desde las perspectivas católicas imperiales, los continuos martirios se desdoblan ideológicamente como títulos de legitimación de la conquista.

\section{Conquista, colonización y evangelización de las Marianas}

La aventura del Nuevo Mundo conllevó la interacción de culturas y creencias en un espacio geográfico desconocido. Las mesnadas y los pobladores europeos fueron los actores que coparticiparon, con los indios, los demás migrantes asiáticos, los esclavos y exesclavos negros, a la definición de realidades originales que dieron vida a nuevas sociedades americanas en incesante construcción (Ciaramitaro, 2015: 631-644). Desde 1492, descubrimiento y conquista procedieron conjuntamente: de las Bahamas los conquistadores se desplazaron antes a Santo Domingo, Cuba, Puerto Rico y Jamaica, luego a las pequeñas Antillas. ${ }^{2}$ Después fue México (1521) y, en seguida, el sur: Yucatán, Chiapas, Guatemala, Nicaragua y Salvador. Mientras se cumplían esas empresas epocales, la esperanza de hallar una vía occidental hacia las Indias orientales quedó vivísima entre los conquistadores: trazando caminos se planearon un sinnúmero de expediciones de amplias y medianas envergaduras para la búsqueda de un istmo transoceánico. Las monarquías española y portuguesa intentaron dirigir y reglamentar los ciclos convulsos de exploración, conquista, asentamiento y configuración de un escenario definitivo.

El "descubrimiento" del Pacífico fue crucial para la vida socioeconómica de México y Perú; estas dos comarcas entraron prontamente en contacto a través de rutas comerciales y marítimas. Las Marianas -cuyas islas más extensas son Guam y Saipán- componen una pieza fundamental en el enredado rompecabezas del descubrimiento y la toma de posesión del océano y, antes del arribo de los europeos, ya algunos grupos de carolinos habían entablado contactos esporádicos con los autóctonos (Pozuelo-Mascaraque, 1997: 50; Coello de la Rosa, 2013a: 91). Las Marianas fueron, pues, el escenario de diversos intentos migratorios, no solo europeos sino también asiáticos. ${ }^{3}$

2 Algunos historiadores separan la primera etapa de la exploración (1492-1495), de la primera colonización (1496-1518) y de la conquista siguiente (1519-1550): “all'inizio del 1495 l'orientamento è già deciso: l'esplorazione porta alla colonizzazione, e la colonizzazione alla conquista. Tutto viene sacrificato all'oro" (Chaunu, 1969: 89).

3 Expediente sobre evangelización de las Islas de los Ladrones o Marianas, AGI, Filipinas, leg. 82, n. 8 . 
Según la tradición -entre los historiadores todavía no hay certidumbre acerca del hecho (Rogers y Ballendorf, 1989)-, el primer explorador occidental que vio el archipiélago fue Fernando de Magallanes, en 1521, que desembarcó en Guam, la isla más meridional de las Marianas, y la reclamó para el emperador Carlos V, denominando el archipiélago de los Ladrones. Sin embargo, desde entonces nada cambió y solo luego de que Andrés de Urdaneta descubriera, en 1565 -aprovechando el monzón del suroeste y pasando por las Californias-, el mejor itinerario marítimo por el cual se podía navegar de las Filipinas a México (el famoso tornaviaje), resultó indispensable localizar unas islas -que en la fantasía europea se llamaron Armenias-, las cuales podrían aprovecharse como escala o sitio de abastecimiento en la navegación pacífica de las embarcaciones que provenían de China.

Un informe del cartógrafo y piloto Francisco Gali, ${ }^{4}$ de 1585 , señala las Armenias como posible puerto intermedio y, tal vez, las islas identificadas eran las Hawái; empero los europeos nunca más volvieron a encontrarlas sino hasta el siglo XVIII (Mathes, 1973: 21-23; Mandrí-Bellot, 1991: 13; PinzónRíos, 2015: 754-755). ${ }^{5}$ Después vinieron las expediciones navales de Pedro de Unamuno, Sebastián Rodríguez Cermeño y Sebastián Vizcaíno, que contribuyeron notablemente a clarificar la geografía del Mar del sur.

Únicamente a partir del siglo XVII, frente a las amenazas de otros países europeos, la corona española decidió una política de mayor efectividad en el control del Pacífico; y después de prohibir, en 1631, el tráfico interamericano México-Perú, considerándolo peligroso para sus privilegios metropolitanos, dispuso un posible proyecto de colonización y evangelización definitivas de las Marianas.

En un muy logrado estudio reciente, Mariano Bonialian (2014: 27-28), recordando el poema Grandeza mexicana (1604) de Bernardo de Balbuena, dibuja una imagen de México como foco del imperio hispánico, efigie que corresponde igualmente a la trazada por otros historiadores, entre ellos, por ejemplo, Pierre Chaunu (1969: 110), que ha remarcado el alcance que desde

4 El obispo-virrey de la Nueva España, Pedro Moya de Contreras (1584-1585), contribuyó a impulsar el hallazgo de un puerto seguro a medio camino entre las 2000 leguas marinas que separaban las Filipinas y Acapulco, que además permitiera a los navíos las posibles reparaciones, la provisión de agua, de atender a los heridos. Francisco Gali, "soldado y hombre prudente", según el factor y veedor de la real hacienda de Filipina Juan Bautista Ramón, fue uno de sus referentes, véase Carta de Juan Bautista Ramón, 22 de junio de 1584, AGI, Filipinas, leg. 6, 2, n. 17.

5 En particular, acerca de las islas Armenias y su “curiosa historia”, véase Gil (1992: 130-134). 
finales del siglo XVI llegan a tener el recorrido terrestre que conecta Veracruz, México y Acapulco, las rutas marinas entre los virreinatos novohispano y peruano, y las que estas provincias tejen con el extremo oriente en la movilización de personas, objetos y metales preciosos. No obstante, Bonialian (2014: 30) subraya la importancia del eje transpacífico que, por medio del navío de Manila, conectaba las Filipinas con Acapulco y el papel de la ruta de la seda china como "elemento más expresivo" de la reciprocidad de larga duración que se definió entre Asia y América, ni una gota de tinta se refiere a las Marianas. ${ }^{6}$ Sin embargo, la colocación estratégica de las islas en los mares del sur ya era patente desde el periodo inicial del descubrimiento: el archipiélago era la puerta de acceso al continente asiático (Del Valle, 1991: 14; Brunal-Perry, 2004: 555).

Así, pues, la historia de la conquista de las islas de los Ladrones se definió a través de una etapa preparatoria de colonización de los españoles en las islas Filipinas (1521-1668). ${ }^{7}$ Por esa razón, la "aventura" imperial en el archipiélago mariano inició tardíamente, en el siglo XVII, y en ella tuvo un papel más incisivo, por lo menos en la primera fase, el estamento religioso, anhelante de extender la frontera católica en las posesiones de la monarquía en el océano Pacífico, aplicando al pie de la letra la metodología del "imperialismo cristiano". Como ha señalado hace un siglo Herbert E. Bolton (1917) -y más recientemente Bernd Hausberger (1997: 63)-, la misión era una típica institución fronteriza de la corona.

En la lengua castellana medieval y del Renacimiento, las cruzadas ${ }^{9}$ para la reconquista de las tierras santas o de los dominios moros de la península

6 Lo mismo en un más reciente estudio de Bonialian (2016).

7 Solo en 1565 la monarquía española se decidió a fundar el primer poblado en el archipiélago de las Filipinas: San Miguel, la actual Cebú (Reichert, 2014: 135).

8 No obstante muchas veces se siga olvidando en la historiografía contemporánea el papel de la propaganda evangélica de la conquista (Ríos, 2015: 20), la "invención de América" y de su "apéndice" territorial e imperial del Pacífico - las Filipinas, sobre todo- no es solamente la consecuencia de un lento proceso de expansión político-militar, económico y demográfico, sino también cultural y religioso: el objetivo de la evangelización de las nuevas poblaciones no pertenecía solo al discurso retorico de la conquista, sino a la praxis y a los métodos cotidianos de la imposición y del gobierno. Los europeos que se aventuraron en las Indias poseían una tecnología del poder compleja, una cultura caracterizada por una efectiva confianza en su centralidad y -elemento más relevante- una religiosidad enfocada en la omnipresente figuración de un dios adorable, torturado y asesinado (Greenblatt, 1994: 32-33).

9 La "cruzada" era la concesión de indulgencias otorgadas por el pontífice romano a los monarcas de Castilla que aprovisionaban tropas para hacer guerra contra los musulmanes de la península y a los que contribuían para mantenerlas. 
ibérica se nombraban generalmente "empresas" o "negocios", términos en los cuales se entremezclan las características y acepciones mercantiles y religiosas: así, el desenlace último del imperialismo cristiano era el de realizar al mismo tiempo la "conversión" de las mercancías y la conversión de las almas (el negotium crucis). ${ }^{10}$ Con todo, para el "negocio de la cruz" fue ineludible el sacrificio -también el postremo, el de la propia vida- de algunos misioneros que intentaron convertir al catolicismo a las poblaciones aborígenes de las Marianas: ${ }^{11}$ el apóstol pionero fue el capuchino Juan Pobre de Zamora, quien alcanzó las islas en $1601{ }^{12}$ los primeros jesuitas murieron entre 1670 y 1685 , en particular durante las dos guerras chamorras, libradas en 1671 y 1684 $1686 ;{ }^{13}$ los recoletos llegaron a Guam en la segunda mitad del siglo XVIII, el 25 de agosto de 1769, y en aquel entonces misionaban en las Marianas solo tres ignacianos: Franz Stengel, Rafael Canicia y Pedro Lampurdanés. ${ }^{14}$

Queda manifiesto cómo la anterior delineación de una más activa movilidad durante el siglo XVII -de personas, embarcaciones y recursos económicos- surge por un renovado interés para las Marianas: en efecto, es a partir de 1593, cuando se empieza a reglamentar la ruta transpacífica, siendo el puerto novohispano de Acapulco el único autorizado para el comercio asiático, ${ }^{15}$ que las islas ganaron, como recuerda Alexandre Coello de la Rosa (2011: 714), mayor utilidad por sus circunstancias logísticas "como centro de avituallamiento de las embarcaciones que se dirigían a uno u otro lado del

10 Así lo recuerda Alain Milhou (1983: 289): la “negociación” de las Indias posee, como el vocablo "empresa", una connotación doble, una mercantil y otra religiosa.

11 Sobre la teología de la misión es todavía imprescindible el aporte de Scaduto (1971: 323), quien define a los jesuitas como "cuerpo volador" sin ataduras a lugares fijos.

12 El expediente de 1608, que da por presentados y aprobados a fray Mateo de Recalde, en nombre de fray Juan Pobre, los cincuenta frailes de la orden de san Francisco que pasaron a Filipinas y Japón, se encuentra en AGI, Indiferente, leg. 2073, n. 72. Véanse, además, Morga (2007: 150-152, 165-166), San Antonio (1738: 131), Rogers (1995: 19), Coello de la Rosa (2010 y 2013a: 86). Rogers y Coello de la Rosa reportan la fecha de 1602; sin embargo, parece que su estancia fue de seis meses desde el año 1601 (Driver, 1983, 1988a: 86 y $1993 ; 1988 b)$.

13 El primer ignaciano asesinado fue el malagueño Luis de Medina (1637-1670) (Baró i Queralt, 2015: 131). La edición crítica de la primera hagiografía sobre Medina ha sido publicada por Coello de la Rosa y Baró i Queralt (2014).

14 En los años treinta del siglo XVIII los jesuitas supuestamente administraban 2697 almas (San Antonio, 1738: 59).

15 Sobre la prohibición de enviar barcos de Perú a China, véase AGI, Patronato, leg. 25, r. 56. Además, véanse Escalona-Agüero (1775: 160-189) y Yuste (2013). 
Pacífico". Y esa atención comparten los coetáneos de la época de la conquista, como el dominico Ignacio Muñoz, quien considera valiosa la "utilidad de estas Islas" por la posibilidad de ofrecer puertos acogedores para las naos de China, que "se hallan fatigadas de rigurosas tormentas en estos confines" levantinos. ${ }^{16}$

Es la ruta de la seda china que permite consolidar el proceso de evangelización de Asia: en el espacio pacífico se diseminaron los religiosos, sobre todo franciscanos, agustinos y iñiguistas, quienes, en sus vaivenes entre occidente y oriente, incorporaron a las culturas europea, americana y asiática diferentes enseñanzas, no solo espirituales sino también socioeconómicas (Zermeño, 2006: 61-108). ${ }^{17}$ En particular, fueron los indipetae, los jóvenes ignacianos que petebant Indias, quienes apetecieron, de día y de noche, despiertos o soñantes, el "beato intento" de una misión en Asia (Roscioni, 2001: $5-7) .{ }^{18}$ Se buscaba el "vivir indiano", que correspondía a una experiencia interior y una elección irreversible; pero tal vez más que un deseo de proselitismo religioso, muchos misioneros ansiaban expresar una manifestación de crisis intelectual de la conciencia (Fabre, 2007). Así fueron, entre otros, el joven catequista Pedro Calúñgsod (1654-1672) ${ }^{19}$ y los padres Diego Luis de San Vítores (1627-1672), Sebastián de Monroy (1649-1676) y Agustín Strobach $(1646-1684),{ }^{20}$ quienes, como su correligionario modélico Francisco Javier, ${ }^{21}$

16 AGN, Reales cédulas originales, v. 14, ff. 263-272. Muñoz, quien vivió entre Manila y Nueva España y realizó unos viajes a Asia, era maestro de teología y filosofía (Reichert, 2014).

17 Véase también la Suma del estado del imperio de la China, y Christiandad dèl, por las noticias que dàn los Padres de la Compañia de Iesvs, que residen en aquel Reyno, hasta el año de 1649, AHN, Diversas colecciones, leg. 27, n. 14, ff. 1-4.

18 El deseo de misión en las Indias entre los jesuitas europeos queda patente en las numerosas litterae indipetarum o indipetentium que todavía se conservan en el archivo romano de la Compañía (Roscioni, 2001; Broggio, 2004: 64). Para una lectura amplia del papel que los imperios ibéricos jugaron en los proyectos misionales y educativos dibujados por los ignacianos desde Roma, así como el lugar que las misiones católicas y los proselitistas ocuparon en la consolidación de los estados, véase Coello de la Rosa et al. (2012).

19 Calúñgsod, asistente de San Vítores, fue martirizado junto a este y canonizado por la iglesia católica en 2012 (Oyola-Fabián y López-Casquete, 2014: 106-107).

20 Sobre el padre bohemio Agustín Strobach, quien no es objeto de estudio en este artículo, se remite a De Boye (1691), Hausberger (2015: 281-308), Fochler (2016). Más en general, acerca de la contribución de la provincia jesuítica de Bohemia para la evangelización de las islas pacíficas, véase Binková (2016a).

21 Francisco Javier era la guía espiritual de los misioneros jesuitas en el siglo XVII (Dompnier, 2002) y no es causal que el ignaciano Diego Luis de San Vítores, en su carta de solicitud de 
se encaminaron al martirio para evangelizar el nuevo mundo de las Marianas. ${ }^{22}$ Ellos fueron la vanguardia de la fe en el Pacífico: con su humillación periódica por el trabajo manual, las dificultosas situaciones del día a día y por el acercamiento a los más toscos o los indígenas, encarnaron la quintaesencia del predicar entre los últimos y la misma identidad jesuítica; ellos cargaron sin duda un peso material y psíquico que no todos podían enfrentar. ${ }^{23}$

Del padre Monroy se conocen escasos datos biográficos: era originario de la villa de Arahal, en el arzobispado de Sevilla, hijo del hidalgo Bartolomé Rodríguez de Monroy y de doña Ana de Perea (Aranda, 1690: 9-10). De San Vítores sabemos que era miembro de una rica familia de mercaderes de Burgos y que estudió, en contra de la voluntad de los padres, en el noviciado de Villarejo de Fuentes, cerca de Cuenca; luego pasó a la universidad de Alcalá y, finalmente, se ordenó sacerdote en 1651 (García, 1683). ${ }^{24}$ Se sabe que en julio de 1659, en una carta al padre general, expresó su precoz deseo de convertir almas y de martirio (Baró i Queralt, 2010: 18); gozó antes del apoyo de Felipe IV y después de su esposa Mariana de Austria; desembarcó en Manila en 1666 y de inmediato quiso recorrer las 300 leguas que separaban las Filipinas del archipiélago de los Ladrones. Sin embargo, su deseo se frustró por la falta de capitales, y para recaudarlos viajó a México, desde donde, gracias a la generosidad del virrey, que le asignó 10,000 pesos del fondo de las Filipinas, pudo organizar la expedición de conversión de los indígenas de las Marianas.

1659 para misionar en las Indias, declarase de querer dedicar toda su vita y fuerza en el ministerio de las misiones bajo la protección de Francisco Javier (García, 1683: 71).

22 Sobre la historia de la colonización y conversión de las Marianas y la vida del apóstol Diego Luis de San Vítores es interesante la traducción y edición italiana del texto de Francisco García (1683), dedicado a la duquesa de Aveiro, “madre de las misiones", que realiza en Nápoles el jesuita español Ambrosio Ortiz (1686). Finalmente, véanse Risco (1970), Saborido-Cursach (1985), Rogers (1995), Ramos-Suárez (2016: 550). Este último investigador recuerda que, en el museo japonés de los 26 mártires de Nagasaki, de San Vítores se conservan ocho cartas, varios otros documentos y la misma sotana con la que fue martirizado. Para una imagen unitaria de la misión jesuita en las islas Marianas entre 1668 y 1769, véase Coello de la Rosa (2014). Sobre las nuevas fronteras misionales en la América del siglo XVII y el "imperio martirial" ignaciano, Cañeque (2016).

23 Desde los momentos fundacionales de la primera mitad del siglo XVI, era esta la praxis en las misiones (Broggio, 2004: 64) y para los jesuitas. La misión se configuró como ministerio fundante de la Compañía. El ignaciano tenía la obligación de buscar el vínculo con los más humildes, con los rudes, era un ejercicio imperativo de su cursus honorum, una dura prueba de accomodatio que hubiera tenido que erigir los fundamentos de su formación y aprendizaje como jesuita y su definición espiritual como sacerdote (Majorana, 2003a: 195-199; 2011).

24 Véase una biografía más reciente del misionero en Saborido-Cursach (1985). 
Al llegar a Guam con otros cuatro correligionarios, en 1668, se estableció en el pueblo de Agaña, en donde se dedicó con fervor al proselitismo religioso. El 2 de febrero de 1669 levantó el primer templo en la región, así como la residencia jesuítica en la nueva plaza de armas y, no obstante las continuas penurias económicas, como demuestra un memorial remitido a la congregación de México, ${ }^{25}$ esparció el mensaje de Cristo en 11 islas del archipiélago (García, 1683: 211).

Gracias al compromiso de los dos padres iñiguistas con la causa evangelizadora de los chamorros, el ejemplo de vida santa y llena de gentileza que reprodujeron, el brío apostólico de hombres que se mostraban como los más afables, suaves y detenidos entre los cristianos, y gracias sobre todo a sus sacrificios mortales, San Vítores y Monroy encarnaron el modelo de dedicación misionera que se propagó en la segunda mitad del siglo XVII en la Europa contrarreformista y en las Indias occidentales y orientales; un "tipo ideal" funcional a la revitalización del entusiasmo catequístico. En palabras del padre Pedro de Calatayud (1754: 7-8), ser misionero significaba ser genio entre los genios, sujeto ardiente, brillante y vivo que, "con virtud proporcionada", era instrumento oportuno de vocación y de gracia para el ministerio.

La literatura que se ha generado en las últimas décadas sobre la misiología y la martiriología es considerable. Los dos fenómenos, muchas veces correlacionados, se pueden observar desde diversos enfoques: entre ellos, por ejemplo, la movilidad, como modalidad irrenunciable para la operación de conversión y la fundamentación de la vida espiritual (Broggio, 2004: 24-25, 318); la palabra, el lenguaje hablado de los misioneros que se comunicaban con los pueblos bárbaros, pero sobre todo el lenguaje escrito de los relatos y avvisi misionales, los que circularon ampliamente como instrumento proselitista para acercar la juventud católica europea al vigor contrarreformista de la propaganda fide o los que se usaban como herramienta interna de comunicación horizontal o jerárquica; ${ }^{26}$ finalmente, entre otros numerosos

25 Memorial que el P. Diego Luys de Sanvitores, religioso de la Compañia de Jesus, Rector de las Islas Marianas remitió á la congregacion del glorioso apostol de las Indias S. Francisco Xavier de la Ciudad de Mexico, pidiendo le ayuden, y socorran para la fundacion de la missión de dichas islas, 1669, JCBL, RIBR00-B2083.

26 Me refiero no solo a las notorias hagiografías de los mártires, traducidas a diferentes idiomas, y a las cartas internas y los informes que circulaban entre los padres, sino también a la narración de los caminos personales e íntimos que conllevaron a numerosos jesuitas (pero también a religiosos de otras órdenes) a solicitar a sus superiores de ser despachados como misioneros a las Indias, son las litterae indipetarum - de las cuales ya se ha hablado-, cartas personales que narran episodios romancescos, el deseo de fuga, descripciones superficiales, 
posibles encauses analíticos, también la iconografía, pinturas, grabados y esculturas que se mostraban a los candidatos a la misión como rápido medio de empatía, para compartir el sentimiento de dolor, el ejemplo virtuoso y la inmolación; ${ }^{27}$ o por clara voluntad pedagógica-devocional que subyace a la representación pictórica o a la grabación: las imágenes se emparejaban con leyendas explicativas de las escenas de martirio, que asimismo servían para los menos cultos como modelos de santidad y praxis católicas; se insistía así en el valor espiritual de la vista y en lo visible como revelación de santidad. ${ }^{28}$ Espécimen indicador del vínculo entre texto y retrato es el volumen del jesuita Mathias Tanner (1630-1692), Societas Jesu usque ad sanguinis et vite profusionem militans..., publicado en Praga (1675), en el cual se reseñan las víctimas de la orden, repartiéndolas por secciones continentales, según el lugar donde recibieron el martirio, Europa, África, América etcétera, y con clara voluntad devocional (Figura 1). ${ }^{29}$

la incertidumbre acerca de algunas conductas de correligionarios, los disensos en materia de política misionera, las aflicciones, el poco edificante deseo de autoafirmación, en suma, historias de vida (Prosperi, 1996: 586-599; Roscioni, 2001: 12, 33, 38, 49, 67, 81-94, 117 118). Sobre la "mediación de la palabra" y la persuasión en el oficio del misionero, véase Prosperi (1991: 181-187); mientras que, para un atento análisis acerca del estilo y lenguaje misioneros de los jesuitas en los primeros dos siglos de la época moderna, para el caso italiano, véase Majorana (2015: 137): la historiadora profundiza sobre la confrontación entre "oratoria cittadina e oratoria missionaria, cioè tra i due diversi ministeri gesuitici", disputa en la que confluye la reflexión acerca del estilo y las lenguas de la predicación rural.

27 Un ejemplo significativo eran los frescos ahora desaparecidos de los mártires jesuitas del refectorio del colegio de San Andrés, en Roma, en los cuales era evidente el espíritu de inmolación que se quería transmitir a los futuros misioneros de las Indias (Roscioni, 2001: 77-79; Majorana, 2003b; Broggio, 2004: 58).

28 Como en los casos más conocidos de la torre del castillo bávaro de Dillingen y la iglesia de Santo Stefano Rotondo en Roma (Nicolaci, 2013: 40-41). Véase también Bargellini (2016: 150). Más en general, sobre el poder de las imágenes y los Visual Studies respecto a la teoría iconográfica cristiana, véase Dekoninck (2016); sobre el análisis del papel de las imágenes misionales, los métodos de evangelización y el intercambio material, cultural y simbólico, véase Fabre (1999: 466-467).

29 Todas las figuras se encuentran en el anexo, al final del presente artículo. Cada reseña de la vida del mártir viene acompañada de un grabado realizado según el dibujo del pintor praguense Karel Škréta, representando el dramático fallecimiento del religioso, empero las efigies, "bastante explícitas en representar la violencia, en su momento no debían provocar temor, más bien exhortar a seguir el ejemplo de los que sacrificaron su vida en difundir la fe cristiana" (Binková, 2016b: 234). 
Tal vez aún más ejemplar resulta el libro Effigies et nomina eorum, qui Societate Jesu per quatuor orbis partes pro Dei et religionis causa sanguinem et vitam profuderunt. Ab anno 1549 usque ad annum 1655 (Anónimo, sin lugar y sin fecha, pero de la segunda mitad del siglo XVII), mera compilación de grabados con martirios de jesuitas, prácticamente sin texto y que con la pura imagen desea infundir recogimiento. ${ }^{30} \mathrm{Y}$ de esta necesidad devocional como para justificar en el discurso retórico y político la conquista hispanocatólica del archipiélago mariano, surge, a través de la figura de Mariana de Austria y "sus" jesuitas, una doble simbolización emblemática, que es monárquica y martirial.

\section{Mariana de Austria en la simbolización monárquico-martirial del archipiélago de los Ladrones}

A fines del siglo XVII aparece, en la ya decadente Sevilla, un grabado holandés de exaltación de la exregente Mariana de Austria, no solo como propulsora de la cristianización jesuítica de las islas Marianas, así llamadas en su honor, sino también como garante del desdoblamiento habsbúrgico-católico del martirio, en título de legitimación de la conquista.

La obra del padre Gabriel de Aranda, Vida, y gloriosa mverte del V. Padre Sebastian de Monroy, religioso de la Compañia de Jesvs, que murio dilatando la Fè alanceado de los barbaros en las Islas Marianas, publicada en Sevilla (1690), y "dedicada a la Avgvstissima Sra. D. Mariana de Avstria, Reyna de España, y protectora de la Christiandad en las Islas Marianas” por Fernando Rodríguez de Monroy, prebendado de la catedral hispalense y hermano del mártir, muestra como contraportada una estampa dirigida "a la Magestad" de la soberana en los mismos términos. ${ }^{31}$

Firmada por Joseph Mulder, la composición personifica en primerísimo plano a la reina en traje de viuda arrodillada sobre un cojín, teniendo en el suelo la corona, de solo dos imperiales cruzados, según el modelo acostumbrado de los Austria españoles, y recibiendo de Sebastián de Monroy, de pie en una nube al más bajo nivel posible, y con nimbo de santidad, un pliego donde se lee: "Islas Marianas Pueblo de Oro se" (Figura 2).

Aunque el escenario es convencionalmente indeterminado, a la izquierda del espectador, a espaldas de la aparición, se ve el arranque de una columna, 30 BUV, I-235624. El volumen, citado pero sin aclarar la debida colocación por Hausberger (1995: 42-43), es un magnífico ejemplo de "poder de las artes" y de la capacidad de persuasión de la imagen que estudia Bailey (1999).

31 Véase también Páez-Ríos (1981: 261, n. 1454, 2 y lámina correspondiente). 
y a la derecha, tras la soberana, un dosel en cuya caída asoma el escudo de las armas reales, reducidas al contracuartelado de Castilla y León. Varios angelitos, tres de ellos sosteniendo un bastón muy alargado, rematan este ejemplo de alegoría monárquica-devota con retrato in assistenza, de un tipo poco habitual bajo los Habsburgo hispanos. Cabe destacar que, en franco contraste con sus numerosas efigies pictóricas, grabadas o incluso dibujadas, el rostro de Mariana no es reconocible, lo cual denota una incomprensible falta de información gráfica al autor, quien, sin embargo, sabe cómo viste el personaje.

De la cara del mártir sale una filacteria con la leyenda "Tu populum humilem salvum facies”, referencia al salterio de David, concretamente al salmo XVII, que, por citar versiones españolas del antiguo régimen, en la de Jacques-Philippe Lallemant (1786: 48), a través de Jaime Serrano, significa "cuidais de salvar al pueblo sujeto á vuestra voluntad", y en la de fray Diego Fernández (1801: 33), “Tú, Señor, harás salvo al pueblo abatido”, frases que solo genéricamente parecen adaptarse al argumento.

Joseph Mulder, nacido en Âmsterdam en 1658 y fallecido en 1728, discípulo de Hendrick Bogaert y también de Romeyn de Hooghe, era, según los repertorios de Josep Strutt (1786: 169) y Michael Bryan (1816: 103$104)$, un artista que, trabajando frecuentemente con sus propios dibujos, desarrolló temas bíblicos e históricos, así como asuntos referentes a las Indias holandesas, si bien se le valoraba ante todo por sus vistas de iglesias y otros edificios públicos. La estampa dedicada a Mariana de Austria ha de ser de su invención, aunque no sobresale precisamente por su despliegue de motivos arquitectónicos. Evidentemente, la ambición iconográfica de la descripción está por encima de las habilidades del autor.

Respecto a la vinculación de Mulder con España, procede señalar, por un lado, que él abrió la portada de la obra Primera parte de la Historia general del Nvevo Reyno de Granada, de Lucas Fernández de Piedrahita, publicada en Amberes (1688) ${ }^{32}$-composición que ofrece una orla con los retratos de los sucesivos soberanos indígenas del territorio (Figura 3)-; y, por otro, que el mencionado Romeyn de Hooghe grabó en 1685 la famosísima acción eucarística de Carlos II cediendo su coche al viático.

En el contexto del respaldo regio a la actuación de los jesuitas en el área de las Filipinas - postura que, como demuestra Coello de la Rosa (2011: 715-716 y 720), vino facilitada por la mediación del padre Juan Everardo Nithard, maestro espiritual y confesor de la viuda-, Mariana manifestó en cédula de 1665 su apoyo a la labor evangelizadora de la Compañía en el

32 Véase Falcón-Márquez (1995: 193, n. 112, ficha de Rocío Caramuel Moyano y Aurora Domínguez Guzmán). 
archipiélago de los Ladrones, para la que también prestó socorro económico, con la consecuencia de que la orden cambió el nombre de las islas, pasando a denominarlas Marianas.

Apenas elevada al gobierno en ese año de 1665, la regente se apresuró a enviar allí al padre Diego Luis de San Vítores, primer apóstol, y en 1673 despachó con el mismo destino a Monroy, quien -como ya se ha mencionado- murió martirizado tres años después, cuando finalmente la misión jesuítica fue reforzada por un destacamento militar remitido por la monarquía (Elizalde, 2016: 409). Solo posteriormente a esa fecha, entre 1679 y 1680 -después de una fase definida por inacabadas o "epidérmicas" conversiones al cristianismo de los naturales, según la locución de Xavier Baró i Queralt (2015: 131)-, la zona parecía haber entrado en un relativamente convencional proceso de aculturación cuyos rasgos característicos no hacían prever un modelo atípico de conquista y de "control" político-ideológico; no obstante, los martirios siguieron perpetrándose.

Como ejemplo de aculturación material, en el marco de las importaciones de ganado y productos alimentarios desde Nueva España, pues las comunicaciones directas con Filipinas no se iniciaron hasta $1683,{ }^{33}$ un iñiguista dijo, en 1679, que los naturales "comen ya carne de puerco y se van aficionando al maíz" -circunstancia que se puede parangonar con otras latitudes del imperio y que refleja una incuestionable mejora en el estilo de vida y la dieta alimentaria-, ${ }^{34}$ conforme al hecho de que "vanse cultivando en lo político, teniendo mayor veneración a los padres, y respecto a los españoles, y les parecen ya bien sus costumbres, especialmente el andar vestidos" (Rodríguez-PongaSalamanca, 1992: 147-149). O sea, en el entramado sociopolítico e internacional del Seiscientos, en el cual la "persuasión dulce" se juzgaba la práctica más apropiada del adoctrinamiento y el papel del misionero resultaba más atrayente (Prosperi, 1991: 180-181), la sociabilidad hispánica, reforzada por el pudor cristiano, triunfaba sobre una desnudez pagana que se iba revelando incompatible con los modificados intereses materiales y morales de los aborígenes. Como señala Marjorie Driver (1988a: 23), la colonia llegaría a estar inextricablemente unida a México y Filipinas por un intenso comercio que afectaría tanto a los indígenas como a los españoles. No en balde, como ya se ha recordado, el galeón de Manila tuvo parada en una de las islas, la de Guam.

Pero en una primera lectura apologética, bajo una óptica político-religiosa, la dimensión histórica preferente del archipiélago cobró pronto otros

33 San Antonio (1738:21) señala que desde las Marianas se traían alcaparras y alcaparrones.

34 Idéntica ocurrencia se puede observar en Nueva España, en las estrategias franciscanas de evangelización de la península yucateca (Peccatiello, 2000: 149 y 152). 
perfiles distintivos. Según Coello de la Rosa (2011: 729 y 741), el triunfo del bien, identificado con los predicadores, sobre el mal, expresado por los autóctonos, "legalizó la posesión española de las Marianas", que, como sostenía un jesuita coetáneo, habían sido regadas "con la sangre de sus mártires”; en otras palabras, "desplegados por el territorio mariano, los símbolos martiriales, como formas de posesión, sirvieron para consolidar la presencia española en la isla”. Pero esa justificación de la conquista por un triunfo que, paradójicamente, se desdoblaba de oblación, un logro tanto más celebrado cuanto más costoso en vidas humanas - pues la ideología del martirio implicaba contradictoriamente la glorificación victoriosa de la aniquilación a manos del enemigo, una muerte hecha vida en términos de "singularidad barroca" sobre la fragilidad e insustancialidad de los bienes mundanos-no era la tónica básica de la evangelización en el área de las Filipinas ni en las Indias occidentales. La legitimación político-religiosa de la conquista por la propagación de la fe no conllevaba la deseabilidad del martirio generalizado a la manera de las Marianas.

Según Eugenia Meyer (1964: 125), cuando fray Gaspar de San Agustín llega en su crónica de Filipinas al año de 1569 -la fecha en que Miguel López de Legazpi recibe el nombramiento de adelantado de las islas de los Ladrones-, deja asomar una tesis providencialista, por lo que plantea la conquista del primero de dichos archipiélagos como una "historia de los vencedores", en la que los españoles siempre ganan. Aquí el argumento sacrificial ha cedido paso a una fórmula más convencional de triunfo.

Por otra parte, el discurso jesuítico martirial de las Marianas incurre en contradicciones insalvables, como patentiza el propio caso del personaje cuya inmolación motiva la estampa de Mulder. En el mismo siglo XVII, el padre Luis de Morales, al escribir la historia de las islas, relata en términos de manifiesta incoherencia la "gloriosa muerte" del padre Sebastián de Monroy, quien, por un lado, exhorta a sus compañeros a tener la dicha de morir por Cristo; y, por otro, se defiende valerosamente de los enemigos hasta que -muy en contra de su voluntad, se entiende- sucumbe a los ataques (Morales y Le Gobien, 2013: 232-234): para lograr el martirio debe existir, en efecto, el ardor de morir y los religiosos asesinados servían de prueba a la eminencia de la Compañía (Hausberger, 2015: 292). ${ }^{35}$

35 Hausberger agrega cómo el mérito jesuita "queda ilustrado detalladamente con los sacrificios que los misioneros aceptaban voluntariamente”. Sin embargo, hay que aclarar que en la historia del cristianismo el martirio no se busca, se sufre: en el martirio se evidencia la verdad del Evangelio y el mártir no muere por sí mismo, sino porque quiere testimoniar frente al opresor su fe en Cristo como última verdad de la existencia. Doy las gracias a Giovanna Fiume por estas consideraciones. Asimismo, véase Fisichella (2005: 441). 
Las Marianas comportan así un caso límite no solo de lectura positiva de una objetiva pérdida, como era la muerte ante el contrario -pues aquí el tema del héroe caído adquiere dimensiones proporcionales alarmantes-, sino también de interferencia de las órdenes religiosas en el control de la conquista. En el personaje caído, representado como soldado de Cristo difunto para la causa patriótica desdoblada del catolicismo y de la hispanidad, la muerte se carga de valencias tan simbólicas de hacerse "muerte positiva", casi saludable para el fundamento de la conquista: se llega justamente a una sustancial anulación del trauma derivado por la constatación del luto sacrificial del misionero que, a través de su mortificación, purifica la tierra colonial. La expiración ya no es quebrantamiento, sino valor, símbolo de pertenencia colectiva y de fidelidad a los principios cristianos. ${ }^{36}$

Enlazando con utopías como la del reino independiente indocristiano del franciscano Toribio de Benavente Motolinía en la Nueva España del siglo $\mathrm{XVI}^{37}$ y, de modo mucho más directo, con las reducciones del Paraguay y la ocupación de la Baja California jesuítica, ${ }^{38}$ la Compañía hizo en las Marianas un curioso experimento de "gobierno conventual", con pleno respaldo de la corona. Afirma Coello de la Rosa (2010:39) que tras la guerra de 1683-1686 contra los indígenas, los jesuitas asumieron el liderazgo religioso y político de las islas como fundadores de un "'estado misionero" en donde sus mártires actuaron como referentes morales de las tierras sometidas". No obstante, la sujeción y cristianización de los martirizadores, calificados de bárbaros, no impedía, bajo una óptica colonialista utópica, reconocerles ciertas virtudes naturales que, en la dinámica de las tensiones habidas entre los propios europeos, venía a equivaler a una desautorización de la conquista, aunque a efectos meramente retóricos. Coello de la Rosa (2013a: 81-82, 84-85 y 88) estima:

36 Inspiradora resulta la consideración de Broggio (2004: 66), que, evidentemente, no coincide con el caso que se está analizando: a lo largo del siglo XVII se reformula el significado del modelo misionero y la heroicidad del negocio ya no se encuentra en el martirio glorificante, sino en la eventualidad que tenía el apóstol de experimentar en sí mismo todas las virtudes más plenas de la religiosidad moderna, o sea, la prudencia, la justicia, la fuerza, la templanza, la caridad, la eterna esperanza y, a través de la oblación más recóndita, la verdadera fe.

37 Para el proyecto utópico de los franciscanos en México y el pensamiento milenarista, entre las numerosas referencias posibles, véase Pacheco-Rojas (2008: 95-119).

38 Como alega Messmacher (1997: 12), para el caso del fracaso misionero de la California -en el cual el californio se desintegró como sociedad y como grupo-, en el periodo 16971768, aquella provincia "pasa, de ser una sociedad indígena sin historia, a tener una historia sin sociedad: la ocupación jesuita de la Baja California, que se inscribe en un proceso de continuidad, llega a conformar una discontinuidad político-religiosa, cultural y demográfica”. 
[...] que a finales del siglo XVII los jesuitas de las Marianas pensaban que el derecho de evangelización se basaba menos en los valores sociales y morales del tomismo (Acosta) que en las teorías universales del neo-estoicismo (Ricci, Valignano), fundamentadas en la ley natural y universal, que permitían la comunicación entre las sociedades humanas y su ulterior conversión al cristianismo.

Y, así, mientras que el hermano predicador Muñoz reconoce a los indios de las Marianas una evidente afabilidad e invita al monarca a persistir con la tarea evangelizadora para dejar misioneros "por cualquiera canal de las Marianas", ${ }^{39}$ el padre Luis de Morales, en su historia del archipiélago, sostenía que los nativos vivían una felicidad primigenia en curso de destrucción bajo la corrupción moral de los gobernadores españoles, por lo que los jesuitas críticos, adoptando frente a los indígenas una "dimensión dialógica que les permitía expresar sus propios puntos de vista”, manipulaban los planteamientos de los aborígenes en testimonios como la arenga supuestamente pronunciada en 1670 por el jefe Hurao contra la pretendida superioridad de la cultura europea, hoy "un icono de la identidad chamorra en Guam" (Coello de la Rosa, 2013b). ${ }^{40}$ Esta inocencia original o a-histórica encontraba oponente o referente negativo en la civilización cristiana española, tal como en efecto desembarcaba en las islas muy a pesar de los desvelos jesuíticos. Y en el mismo sector del Pacífico hispano se hacía patente el influjo aún más deletéreo de otra cultura desarrollada pero no europea. El jesuita padre Francisco Colin (1633: 242), recogiendo materiales de un hermano de religión, el padre Pedro Chirino, dice que bajo Felipe II el aparato político filipino se quejó al rey contra los chinos residentes en ese otro archipiélago, "por los muchos vicios, y pecados que enseñan a los Indios, particularmente el nefando".

Así, puede sorprender no ya que el comitente de la estampa y del libro sea un prebendado ajeno a la cúspide monárquica y jesuítica y que actúa por motivaciones familiares, sino también, a la inversa, que ni la Compañía ni la realeza acometieran empresas conmemorativas similares, ligadas o no a un Sebastián de Monroy, cuya trayectoria no constituye el máximo espécimen de esta conquista. En la misma línea, no podemos dejar de extrañarnos de que casi no exista una iconografía de los jesuitas muertos por su fe en las islas Marianas, mientras que sí haya una y muy difundida de los mártires de Nagasaki, ejecutados en 1597 , y casi todos japoneses. ${ }^{41}$

39 AGN, Reales cédulas originales, v. 14, ff. 263-272.

40 Sobre la elocuencia del discurso de Hurao y sus valencias históricas, véase Ginzburg (1999: 71-91).

41 La iconografía de los mártires japoneses de 1597 es inmensa, en la península ibérica y el mundo; sin embargo, para el arte español, según Alonso-Sesé (2013), es un tema poco recurrente. 
Por los años en que apareció el libro del padre Gabriel de Aranda, con la estampa de exaltación monárquico-martirial de la reina, la Compañía de Jesús desarrollaba una tipología gráfica de propaganda de su acción misional que no dudaba en recurrir a la simbología más desinhibida, como ejemplifica una estampa mexicana. En efecto, la portada del libro Historia de la Provincia de la Compañia de Jesvs de Nveva-España, del padre Francisco de Florencia (1694), en su primer tomo -en total la Historia tiene ocho volúmenes-, presenta un globo terrestre que emerge en medio círculo describiendo gran parte del continente entre los mares del norte y del sur y, como remate del orbe, la efigie de san Ignacio, desde cuyo corazón se proyectan rayos hasta los de Francisco Javier y Francisco de Borja -aunque no se ven las respectivas vísceras, marcadas por el anagrama jesuítico- que, refractándose, caen sobre varios personajes representativos de los mundos exóticos (Figura 4).

Ya estaba difundida la escenográfica imagen tardobarroca del rayo partido o multiplicado, no exclusiva de la orden. La luz irradiada por el nombre de Jesús proporciona el argumento de una estampa que adorna la portada del Novus atlas sinensis, del jesuita italiano Martino Martini, publicado en Ámsterdam en 1655, obra inseparable de los afanes misionales de la Compañía (Figura 5). ${ }^{42}$ De la imagen cristológica del sol, a la izquierda, sale un rayo que, tras dar en un espejo portado por una figura femenina con atuendo pontificio, se refracta contra una antorcha, símbolo de cómo la fe abraza los corazones de los fieles (Doménech-García, 2012: 334).

El ámbito geográfico y cultural donde se insertan las islas Marianas, es decir, el de las Filipinas, también conoce el manejo retórico del rayo para ilustrar la gloria de la cristianización. Una estampa del libro de fray Gaspar de San Agustín, Conquista de las Islas Philipinas: la temporal por las armas del señor Don Phelipe Segundo el Prudente; y la espiritual, por los religiosos del Orden de Nuestro Padre San Augustin: Fundacion, y progressos de su provincia del Santissimo Nombre de Jesus, publicado en Madrid, en 1698, muestra sobre el mapa del territorio un sol naciente, por encima del cual otro sol, con el anagrama de Jesús, da en un corazón que lleva en la mano san Agustín, y cómo el rayo, refractándose, se divide en otros dos que caen sobre el archipiélago, complejo asunto flanqueado por dos grupos de personajes, el profano, a la derecha, con Felipe II y tras él Miguel López de Legazpi, y el religioso, con dos de los frailes que acompañaron al conquistador (Figura 6) (Aa.Vv., 1993: 155-156, n. 132, ficha de Fernando Bouza). Detalle un tanto excesivo de humillación regia ante un venerable padre de ínfimo rango en el universo

42 Sobre Asia, la sinología y los estudios de Martino Martini, véase Mungello (1989: 106-133). 
sobrenatural católico, y quien, por otra parte, representa directísimamente los intereses de una determinada orden conventual que interactúa con el imperio en una empresa de conquista; el de la corona en el suelo puede ser capricho del grabador Mulder, signo genérico de humildad devota. Pero objetivamente indica renuncia a los poderes mundanos, como se ve, por ejemplo, y ejemplo insigne, en la pintura dinástica por excelencia, La gloria, de Tiziano, de 1551-1554. ${ }^{43}$

\section{Conclusiones}

En el siglo XVII, el lento proceso de ocupación del área de los Ladrones y de su cristianización se realizó también bajo la imaginería simbólica del martirio ignaciano y de la reina Mariana de Austria, guardiana de la verdadera fe en las islas. La Compañía de Jesús, "cuerpo volador” y tropa voluntaria al servicio del papa, del imperio español y del catolicismo, reglamentada en su modus operandi para la ejecución de la gloria divina y el perfecto servicio de las almas de los chamorros, cumplió una peligrosa faena de conversión en la que, desde la mirada de la soberanía habsbúrgica, los martirios del burgalés Diego Luis de San Vítores, del malagueño Sebastián de Monroy y de los demás iñiguistas se desdoblaron ideológicamente como título justificativo de la presencia y del gobierno hispánicos.

La tónica ideológica del suplicio en las Marianas, analizada a través de la presencia jesuita y del diseño martirial y devocional de la misma reina, no constituye una excepción en el panorama apostólico de las Filipinas y las Indias occidentales, porque se revela una interferencia evidente del brazo religioso en la gestión política de la conquista; sin embargo, en el archipiélago, la intervención misional se constata enormemente débil en las modalidades de penetración del mensaje católico y civilizador, y en la relación entre los predicadores-mártires y los evangelizados: los jesuitas de las islas Marianas no se insertaron cabalmente en el antiguo orden prehispánico local.

\section{Archivos y bibliotecas}

AGI, Archivo General de Indias, Sevilla. AGN, Archivo General de la Nación, México. AHN, Archivo Histórico Nacional, Madrid.

43 En La gloria, el emperador Carlos V tiene la corona expresiva de su suprema jerarquía monárquica sobre la nube en que se haya arrodillado, una forma de señalar que está a sus pies, como simple recordatorio de vanas glorias terrenales. 
Fernando Ciaramitaro. Política y religión: martirio jesuita y simbolización monárquica de las Marianas

BUV, Biblioteca de la Universidad, Viena.

JCBL, The John Carter Brown Library, Providence.

\section{Referencias}

Aa.Vv. (1993), Los Austrias. Grabados de la Biblioteca Nacional, España: Biblioteca Nacional-J. Ollero.

Alonso-Sesé, Rocío (2013), "Los 26 mártires de Nagasaki. Contextualización en el arte hispánico", en Fòrum de recerca, núm. 18, España: Universitat Jaume I de Castelló.

Anónimo (s.f.), Effigies et nomina eorum, qui Societate Jesu per quatuor orbis partes pro Dei et religionis causa sanguinem et vitam profuderunt. Ab anno 1549 usque ad annum 1655, s.l.: s.e.

Aranda, Gabriel de (1690), Vida, y gloriosa mverte del V.padre Sebastian de Monroy, religioso de la Compañia de Jesvs, Que muriò dilatando la Fè alanceado de los barbaros de las Islas Marianas, España: T. López de Haro.

Bailey, Gauvin Alexander (1999), Art on the Jesuit Missions in Asia and Latin America, 1542-1773, Canadá: University of Toronto Press.

Bargellini, Clara (2016), "Consideraciones sobre imágenes jesuitas en la Nueva España y sus fuentes grabadas”, en Progressus, núm. 3-2, Italia: Università di Siena.

Baró i Queralt, Xavier (2010), "Redescubriendo a Diego Luis de San Vítores (16271672): su actitud ante los nativos de Las Marianas y su obra sobre San Francisco Javier (1661)", en Revista Española del Pacifico, núm. 23, España: Asociación Española de Estudios del Pacífico.

Baró i Queralt, Xavier (2015), "La construcción del modelo hagiográfico: San Gregorio Magno versus los misioneros españoles en las islas Marianas (siglo XVII)", en Medievalia, núm. 18-1, España: Universitat Autònoma de Barcelona.

Barratt, Glynn (2003), The Chamorros of the Mariana Islands: Early European Records, 1521-1721, Marianas: Commonwealth of the Northern Mariana Islands-Division of Historic Preservation.

Binková, Simona (2016a), "Contribución de los jesuitas de la Provincia de Bohemia para la evangelización de las islas Filipinas y Marianas y para su conocimiento en Europa central”, en Binková, Simona y Křížová, Markéta [eds.], Ir más allá... Fuentes bohemicales para el estudio comparativo de la expansión colonial española en la temprana Edad Moderna, República Checa: Universidad Carolina de Praga.

Binková, Simona (2016b), "El triángulo Bohemia-México-las islas Filipinas y Marianas", en Binková, Simona y Kř́ížová, Markéta [eds.], Ir más allá... Fuentes bohemicales para el estudio comparativo de la expansión colonial española en la temprana Edad Moderna, República Checa: Universidad Carolina de Praga.

Bolton, Herbert (1917), “The Mission as a Frontier Institution in the Spanish-American Colonies”, en American Historical Review, núm. 23, Estados Unidos: American Historical Association.

Bonialian, Mariano (2014), China en la América colonial: bienes, mercados, comercio y cultura del consumo desde México hasta Buenos Aires, México-Argentina: Instituto Mora-Biblos.

Bonialian, Mariano (2016), "La 'ropa de la China' desde Filipinas hasta Buenos Aires. Circulación, consumo y lucha corporativa, 1580-1620”, en Revista de Indias, núm. LXXVI-268, España: Consejo Superior de Investigaciones Científicas. 
Convergencia Revista de Ciencias Sociales, núm. 78, 2018, Universidad Autónoma del Estado de México

Broggio, Paolo (2004), Evangelizzare il mondo. Le missioni della Compagnia di Gesù tra Europa e America (secoli XVI-XVIII), Italia: Carocci.

Brunal-Perry, Omaira (1997), Indice de documentos relativos a las Islas Marianas y Carolinas, siglo XIX: provenientes del Archivo del Ministerio de Asuntos Exteriores de España ( $A M A E)$, Guam: Micronesian Area Research Center-University of Guam.

Brunal-Perry, Omaira (2004), "Las islas Marianas: enclave estratégico en el comercio entre México y Filipinas”, en Cabrero, Leoncio [ed.], España y el Pacifico. Legazpi (Conmemoración del $V$ Centenario de la Expedición de Miguel López de Legazpi a Filipinas), España: Sociedad Estatal de Conmemoraciones Culturales.

Bryan, Michael (1816), A biographical and critical dictionary of painters and engravers [...], vol. 2, Reino Unido: Carpenter and Son, J. Booker-Whittingham and Airliss.

Calatayud, Pedro de (1754), Missiones y Sermones del P. Pedro de Catalayud, Maestro de Theologia, y Misionero Apostolico de la Compañia de Jesus, de la Provincia de Castilla [...], España: E. Bieco.

Cañeque, Alejandro (2016), "Mártires y discurso martirial en la formación de las fronteras misionales jesuitas”, en Relaciones, núm. 145, México: El Colegio de Michoacán.

Chaunu, Pierre (1969), L'America e le Americhe. Storia del continente americano, Italia: Dedalo Libri.

Ciaramitaro, Fernando (2015), "Gli italiani del Nuovo Mondo: conquistatori, colonizzatori ed evangelizzatori”, en Ríos, Martín F. [ed.], El mundo de los conquistadores, MéxicoEspaña: Universidad Nacional Autónoma de México y Sílex.

Coello de la Rosa, Alexandre (2010), "Colonialismo y santidad en las islas Marianas: los soldados de Gedeón (1676-1690)”, en Hispania, núm. LXX-234, España: Consejo Superior de Investigaciones Científicas.

Coello de la Rosa, Alexandre (2011), "Colonialismo y santidad en las islas Marianas: la sangre de los mártires (1668-1676)”, en Hispania sacra, núm. LXIII-128, España: Consejo Superior de Investigaciones Científicas.

Coello de la Rosa, Alexandre (2013a), "Colonialismo, resistencia e identidad chamorra en la misión post-jesuita de las islas Marianas (1769-1831)”, en Estudios de Historia Novohispana, núm. 49, México: Universidad Nacional Autónoma de México.

Coello de la Rosa, Alexandre (2013b), "Introducción”, en Morales, Luis de y Le Gobien, Charles (2013), Historia de las islas Marianas, España: Polifemo.

Coello de la Rosa, Alexandre (2014), "Jesuits at the Margins: Missions and Missionaries in the Mariana Islands (1668-1769)", en Anais de História de Além-Mar, núm. 15, Portugal: CHAM (Centro de Humanidades).

Coello de la Rosa, Alexandre et al. [eds.] (2012), Jesuitas e imperios de ultramar. Siglos XVI$X X$, España: Sílex.

Coello de la Rosa, Alexandre y Baró i Queralt, Xavier [eds.] (2014), Luis de Medina SJ. Protomártir de las islas Marianas (1637-1670), España: Sílex.

Colin, Francisco (1663), Labor evangelica, ministerios apostolicos de los obreros de la Compañia de Iesvs, fundacion, y progresos de sv provincia en las Islas Filipinas [...], parte primera, sacada de los manvscriptos del padre Pedro Chirino, España: J. Fernández de Buendía.

Coomans, Peter (1997), History of the mission in the Mariana Islands: 1667-1673, Marianas: Division of Historic Preservation-Commonwealth of Mariana Islands.

De Boye, Emmanuele (1691), Vita et obitus venerabilis patris Augustini Strobach [...], República Checa: J.J. Kylian. 
Dekoninck, Ralph (2016), "La force en puissance des images. Les visual studies au regard de la théorie chrétienne de l'image, XVI ${ }^{e}-\mathrm{XVII}^{\mathrm{e}}$ siècles", en Bartholeyns, Gil [ed.], Politiques visuelles, Francia: Les presses du réel.

Del Valle, Teresa (1991), The Importance of the Marianas Islands to Spain at the Beginning of the Nineteenth Century, Guam: Marc-University of Guam.

Doménech-García, Sergi (2012), "La imagen de San Francisco de Borja y el discurso de la Compañía de Jesús en la evangelización del Nuevo Mundo”, en García-Hernán, Enrique y Ryan, María del Pilar [eds.], Francisco de Borja y su tiempo. Politica, religión y cultura en la Edad Moderna (Actas del Congreso Internacional, Universidad CEU Cardenal Herrera-Instituto de Historia del Consejo Superior de Investigaciones Científicas, Valencia, 7-9 de abril de 2010), España-Italia: Albatros e Institutum Historicum Societatis Iesu.

Dompnier, Bernard (2002), "Mission lointaine et spiritualité sacerdotale au XVII siècle”, en Routhier, Gilles y Laugrand, Frédéric [dirs.], L'espace missionnaire. Lieu d'innovations et de rencontres interculturelles. Actes du colloque de l'Association francophone oecuménique de missiologie, Québec, Canada, 23-27 août 2001, Canadá: Karthala et Presses de l'Université Laval.

Driver, Marjorie G. (1983), "Notes and Documents. Fray Juan Pobre de Zamora and his Account of the Mariana Islands", en The Journal of Pacific History, núm. 18-3, Reino Unido: Routledge.

Driver, Marjorie G. (1988a), "Cross, sword, and silver: The nascent Spanish colony in the Mariana Islands”, en Pacific Studies, núm. 11-3, Estados Unidos: Polynesian Cultural Center.

Driver, Marjorie G. (1988b), "Fray Juan Pobre de Zamora: Hitherto Unpublished Accounts of his Residence in the Mariana Islands", en The Journal of Pacific History, núm. 23-1, Reino Unido: Routledge.

Driver, Marjorie G. (1993), The account of Fray Juan Pobre's residence in the Marianas, 1602, Guam: R. Flores Taitano Micronesian Areas Research Center y University of Guam.

Driver, Marjorie G. (2000), The Augustinian Recollect Friars in the Mariana Islands: 17691908, Guam: University of Guam.

Driver, Marjorie G. (2005), The Spanish Governors of the Mariana Islands: Notes on Their Activities and the Saga of the Palacio, Their Residence and the Seat of Colonial Government in Agaña, Guam, Guam: R. Flores Taitano Micronesian Area Research Center-University of Guam.

Driver, Marjorie G. y Brunal-Perry, Omaira [eds.] (1996), Carolinians in the Mariana Islands in the 1800s: Selected Documents from the Holdings of the Spanish Documents Collection at the Micronesian Area Research Center, Guam: Division of Historic PreservationDepartment of Community and Cultural Affairs-Commonwealth of the Northern Mariana Islands.

Elizalde, María Dolores (2016), "El Pacífico del siglo XIX”, en Yuste-López, Carmen y Pinzón-Ríos, Guadalupe [coords.], A 500 años del hallazgo del Pacifico. La presencia novohispana en el Mar del Sur, México: Universidad Nacional Autónoma de México.

Escalona-Agüero, Gaspare de (1775), Gazophilacium regium perubicum [...], España: Blasii Roman.

Fabre, Pierre Antoine (1999), "Histoire des arts visuels”, en Revue de synthèse, núm. 120/2-3, Francia: Centre National du Livre-École Normale Supérieure. 
Convergencia Revista de Ciencias Sociales, núm. 78, 2018, Universidad Autónoma del Estado de México

Fabre, Pierre Antoine (2007), "Saggio di geopolitica delle correnti spirituali. Alonso Sánchez tra Madrid, il Messico, le Filippine, le coste della Cina e Roma (1579-1593)”, en Aa.Vv., I gesuiti ai tempi di Claudio Acquaviva. Strategie politiche, religiose e culturali tra Cinque e Seicento, Italia: Morcelliana.

Falcón-Márquez, Teodoro [comp.] (1995), Exposición “Universitas Hispalensis”. Patrimonio de la Universidad de Sevilla (alcázar de Sevilla), España: Universidad de Sevilla.

Fernández, Diego (1801), Traducción literal del Salterio de David al idioma castellano [...], España: A. Espinosa.

Fernández de Piedrahita, Lucas (1688), Primera parte de la Historia general del Nvevo Reyno de Granada, Bélgica: J.B. Verdussen.

Fisichella, Rino (2005), "La credibilità della rivelazione cristiana”. Disponible en: https:// books.google.com.mx/books? isbn=8831133527 [7 de abril de 2018].

Florencia, Francisco de (1694), Historia de la Provincia de la Compañia de Jesvs de NvevaEspaña, vol. I, México: J.J. Guillena Carrascoso.

Fochler, Pavel (2016), "Las islas Marianas y el Padre Agustín Strobach, S.J.”, en Binková, Simona y Kř́ízová, Markéta [eds.], Ir más allá... Fuentes bohemicales para el estudio comparativo de la expansión colonial española en la temprana Edad Moderna, República Checa: Universidad Carolina de Praga.

García, Francisco (1683), Vida y Martyrio de el Venerable Padre Diego Luis de Sanvitores de la Compañia de Jesús, Primer Apostol de las Islas Marianas y sucesos de estas Islas desde el año de mil seiscientos y sesenta y ocho, asta el de mil seiscientos y ochenta y uno, España: I. García Infanzón.

Gil, Juan (1992), Miti e utopie della scoperta. Oceano Pacifico: l'epopea dei navigatori, Italia: Garzanti.

Ginzburg, Carlo (1999), History, Rhetoric, and Proof, Alemania-Reino Unido: Historical Society of Israel y University Press of New England.

Greenblatt, Stephen (1994), Meraviglia e possesso. Lo stupore di fronte al Nuovo Mondo, Italia: il Mulino.

Hausberger, Bernd (1995), Jesuiten aus Mitteleuropa im kolonialen Mexiko: eine BioBibliographie, Austria: Verlag für Geschichte und Politik.

Hausberger, Bernd (1997), "La vida cotidiana de los misioneros jesuitas en el noroeste novohispano”, en Estudios de Historia Novohispana, núm. 17, México: Universidad Nacional Autónoma de México.

Hausberger, Bernd (2015), Miradas a la misión jesuita en la Nueva España, México: El Colegio de México.

Ibáñez del Carmen, Aniceto (1998), Chronicle of the Mariana Islands by Father Aniceto Ibánez del Carmen, O.A.R. and Others, Guam: R. Flores Taitano Micronesian Areas Research Center y University of Guam.

Lallemant, Jacques-Philippe (1786), Los Salmos de David y cánticos sagrados [...], España: B. Cano.

Majorana, Bernadette (2003a), “'Schola Affectus'. Persona e personaggio nell'oratoria dei missionari popolari gesuiti”, en Pontremoli, Alessandro [ed.], II volto e gli affeti. Fisiognomica ed espressione nelle arti del Rinascimento. Atti del Convegno di studi, Torino, 28-29 novembre 2001, Italia: L.O. Olschki.

Majorana, Bernadette (2003b), "Images et culture de mission”, en Tapié, Alain [ed.], Baroque vision jésuite. Du Tintoret à Rubens, Francia: Somogy éditions d'art. 
Fernando Ciaramitaro. Política y religión: martirio jesuita y simbolización monárquica de las Marianas

Majorana, Bernadette (2011), “Siendo y mostrándose’. Silvestro Landini missionario gesuita: fondamenti spirituali di un modello di apostolato (1540-54)", en Dall'Olio, Guido et al. [eds.], La fede degli italiani. Per Adriano Prosperi, Italia: Scuola Normale Superiore.

Majorana, Bernadette (2015), "Lingua e stile nella predicazione dei gesuiti missionari in Italia (XVI-XVIII secolo)”, en Mélanges de la Casa de Velázquez, núm. 45-1, España: Casa de Veláquez.

Mandrí-Bellot, José Antonio (1991), “Navegación de Sebastián Vizcaíno”, en Aa.Vv., España y Nueva España: sus acciones transmaritimas. Memorias del I Simposio Internacional, celebrado en la ciudad de México, del 23 al 26 de octubre de 1990, México: Instituto Nacional de Bellas Artes, Consejo Nacional para la Cultura y las Artes, Universidad Iberoamericana y Condumex.

Mathes, Michael W. (1973), Sebastián Vizcaino y la expansión española en el océano Pacifico 1580-1630, México: Universidad Nacional Autónoma de México.

Messmacher, Miguel (1997), La búsqueda del signo de Dios. Ocupación jesuita de la Baja California, México: Fondo de Cultura Económica.

Meyer, Eugenia (1964), "Fray Gaspar de San Agustín, cronista de Filipinas”, en Anuario de historia, núm. 4, México: Universidad Nacional Autónoma de México.

Milhou, Alain (1983), Colón y su mentalidad mesiánica en el ambiente franciscanista español, España: Casa Museo Colón.

Morales, Luis de y Le Gobien, Charles (2013), Historia de las islas Marianas, España: Polifemo.

Morga, Antonio de (2007), Sucesos de las islas Filipinas, México: Fondo de Cultura Económica.

Mungello, David E. (1989), Curious Land. Jesuit Accommodation and the Origins of Sinology, Estados Unidos: University of Hawaii.

Nicolaci, Michele (2013), "Il cardinale d'Augusta Otto Truchsess von Waldburg (15141573). Mecenate della Controriforma”, en Gallo, Marco [ed.], Principi di Santa Romana Chiesa. I cardinali e l'arte. Quaderni delle giornate di studio, Italia: Gangemi.

Ortiz, Ambrosio (1686), Istoria Della Conuersione alla nostra Santa Fede dell'Isole Mariane, dette prima de'ladroni [...], Italia: C. Cavallo y M.L. Mutij.

Oyola-Fabián, Andrés y López-Casquete, Manuel (2014), "Localización de las reliquias del jesuita frexnense Manuel Solórzano y Escobar (1649-1684), evangelizador de las Islas Marianas", en Iñesta-Mena, Félix et al. [coords.], España, el Atlántico y el Pacífico y otros estudios sobre Extremadura, España: Sociedad Extremeña de Historia.

Pacheco-Rojas, José de la Cruz (2008), Milenarismo tepehuán: mesianismo y resistencia indigena en el norte novohispano, México: Siglo XXI y Universidad Juárez del Estado de Durango.

Páez-Ríos, Elena (1981), Repertorio de grabados españoles en la Biblioteca Nacional, vol. 2 (H-Q), España: Ministerio de Cultura.

Peccatiello, Roberta Emanuela (2000), “Strategie francescane e taumaturgie nell' evangelizzazione della penisola yucateca”, en Fiume, Giovanna [ed.], Il santo patrono e la città. San Benedetto il Moro: culti, devozioni, strategie di età moderna, Italia: Marsilio.

Pinzón-Ríos, Guadalupe (2015), "Descubriendo el Mar del Sur de los puertos novohispanos en las exploraciones del Pacífico (1522-1565)”, en Ríos, Martín F. [ed.], El mundo de los conquistadores, México-España: Universidad Nacional Autónoma de México-Sílex. 
Convergencia Revista de Ciencias Sociales, núm. 78, 2018, Universidad Autónoma del Estado de México

Pozuelo-Mascaraque, Belén (1997), "Presencia y acción españolas en las islas Marianas (1828-1898)", tesis de doctorado en Historia, España: Universidad Complutense.

Prosperi, Adriano (1991), "Il missionario", en Villari, Rosario [ed.], L'uomo barocco, Italia: Laterza.

Prosperi, Adriano (1996), Tribunali della coscienza. Inquisitori, confessori, missionari, Italia: Einaudi.

Ramos-Suárez, Manuel Antonio (2016), “Doña María Guadalupe de Lancaster, duquesa de Aveiro, y su devoción a los mártires del Japón”, en Gómez-Aragón, Anjhara [ed.], Japón y Occidente. El patrimonio cultural como punto de encuentro, España: Aconcagua Libros.

Reichert, Rafal (2014), "La transcripción del manuscrito de fray Ignacio Muñoz sobre el proyecto de manutención y extensión de la fe católica en las Islas Marianas, y del descubrimiento y la conquista de las Islas Salomón, siglo XVII", en Estudios de Historia Novohispana, núm. 51, México: Universidad Nacional Autónoma de México.

Ríos, Martín F. (2015) [ed.], El mundo de los conquistadores, México-España: Universidad Nacional Autónoma de México-Sílex.

Risco, Alberto (1970), The apostle of the Marianas. The life, labors, and martyrdom of Ven. Diego Luis de San Vitores, 1627-1672, Guam: Diócesis de Agana.

Rodríguez-Ponga-Salamanca, Rafael (1992), "De la Nueva España a las islas Marianas: los cerdos y el vocabulario porcino", en Barrón, María Cristina [ed.] La presencia novohispana en el Pacifico insular. Actas de las Segundas Jornadas Internacionales (México, 17-21 de septiembre de 1990), México: Universidad Iberoamericana.

Rogers, Robert F. (1995), Destiny's Landfall. A History of Guam, Estados Unidos: University of Hawaii.

Rogers, Robert F. y Ballendorf, Dirk A. (1989), "Magellan's Landfall in the Mariana Islands”, en The Journal of Pacific History, núm. 24-2, Reino Unido: Routledge.

Roscioni, Gian Carlo (2001), Il desiderio delle Indie. Storie, sogni e fughe di giovani gesuiti italiani, Italia: Einaudi.

Saborido-Cursach, José Luis (1985), ...Hasta los confines de la Tierra. Diego Luis de San Vitores, s.j., España: Sal Terrae.

San Antonio, Juan Francisco de (1738), Chronicas de la Apostolica Provincia de S. Gregorio de religiosos descalzos de N. S. P. S. Francisco en las islas Philipinas, China, Japon, \& c. Parte primera [...], Filipinas: J. del Sotillo.

Scaduto, Mario (1971), "La strada e i primi gesuiti", en Archivum Historicum Societatis Iesu, núm. 80-40, Italia: Compañía de Jesús.

Strutt, Josep (1786), A biographical dictionary; containing an historical account of all the engravers [...], vol. II, Reino Unido: J. Davis for R. Faulder.

Tanner, Mathias (1675), Societas Jesu usque ad sanguinis et vite profusionem militans, in Europa, Africa, Asia, et America, contra gentiles, mahometanos, judeos, hereticos, impios [...], República Checa: Universitatis Carolo-Ferdinandex.

Yuste, Carmen (2013), "De la libre contratación a las restricciones de la permission. La andadura de los comerciantes de México en los giros iniciales con Manila, 1580-1610", en Bernabeu, Salvador y Martínez-Shaw, Carlos [ed.], Un océano de seda y plata: el universo económico del Galeón de Manila, España: Consejo Superior de Investigaciones Científicas.

Zermeño, Guillermo [ed.] (2006), Cartas edificantes y curiosas de algunos misioneros jesuitas del siglo XVIII. Travesias, itinerarios, testimonios, México: Universidad Iberoamericana. 
Anexo

\section{Figura 1}

Martirización del aragonés Alejandro López y el napolitano Juan de Montiel, asesinados por orden del sultán Muhammad Dipatuan Kudarat en Mindanao, en 1655

\section{Societas Asiatica.}

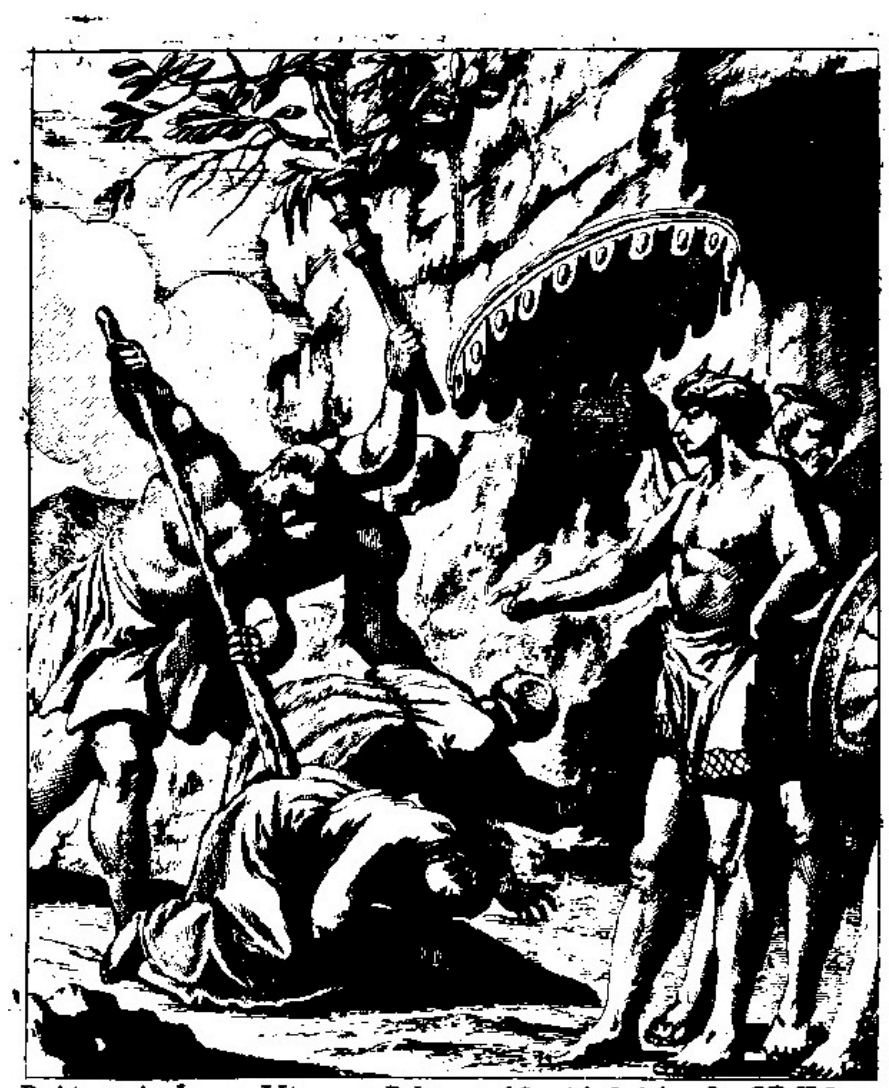

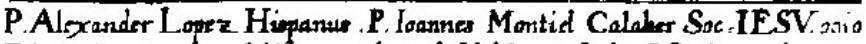
Fidei Christience onedditer truridati ab Idalalatrio Indis. Mindanai $A_{i} \sigma_{5:}$ 13: Desembris.

C.S. 1 M. K:

Fuente: Tanner, Societas Jesu usque ad sanguinis, p. 430. 


\section{Figura 2}

Contraportada de Aranda, Vida, y gloriosa muerte del V.padre Sebastian de Monroy

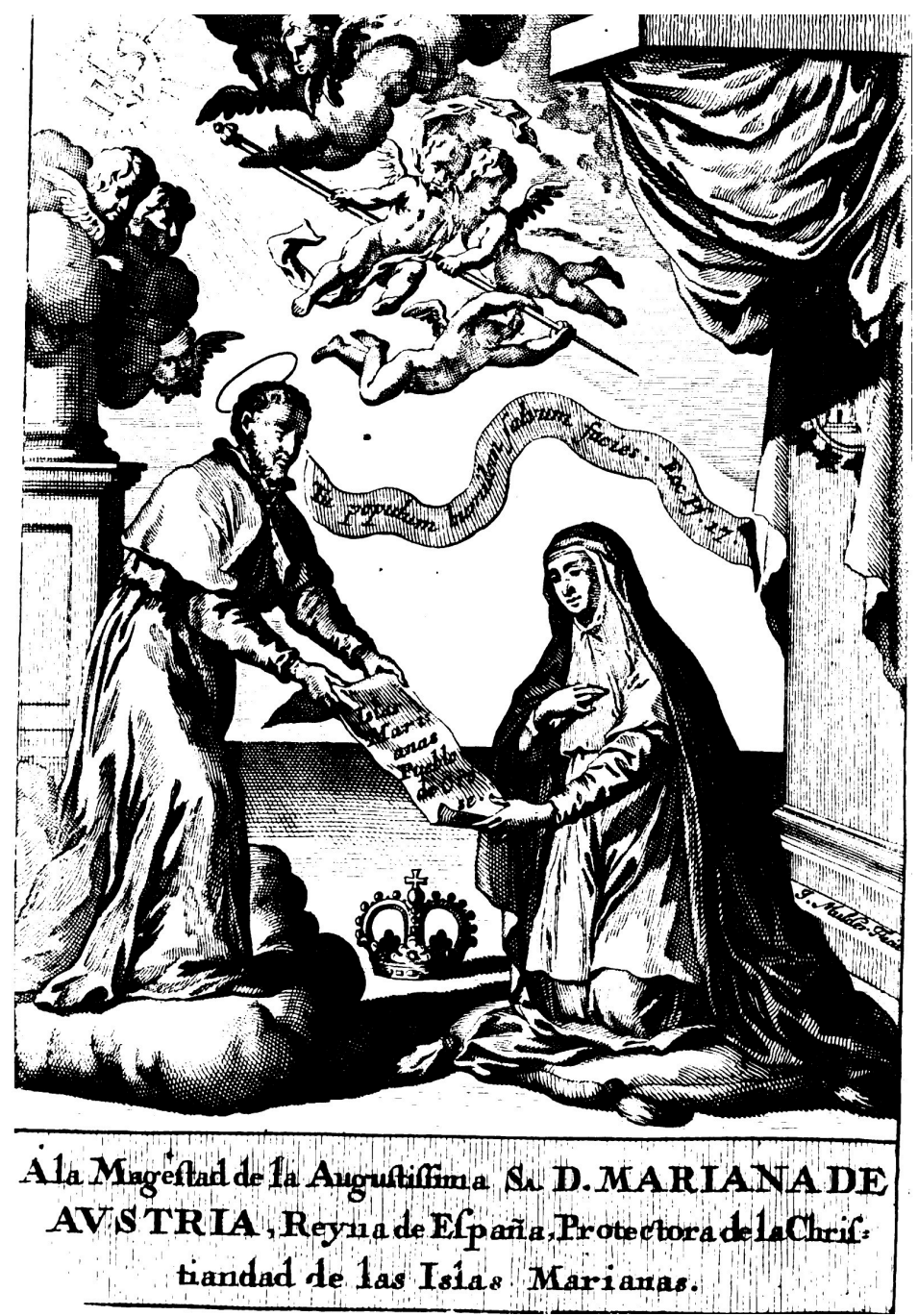


Fernando Ciaramitaro. Política y religión: martirio jesuita y simbolización monárquica de las Marianas

Figura 3

Portada de Fernández de Piedrahita, Primera parte de la Historia general




Figura 4

Portada de Florencia, Historia de la Provincia de la Compañia de Jesvs




Fernando Ciaramitaro. Política y religión: martirio jesuita y simbolización monárquica de las Marianas

\section{Figura 5}

\section{Portada de Martino Martini, Novus atlas sinensis, Ámsterdam, 1655}




Convergencia Revista de Ciencias Sociales, núm. 78, 2018, Universidad Autónoma del Estado de México

Figura 6

Estampa del libro de fray Gaspar de San Agustín, Conquista de las Islas

Philipinas: la temporal por las armas del señor Don Phelipe Segundo el Prudente; y la espiritual, por los religiosos del Orden de Nuestro Padre San Augustin [...], Madrid, 1698

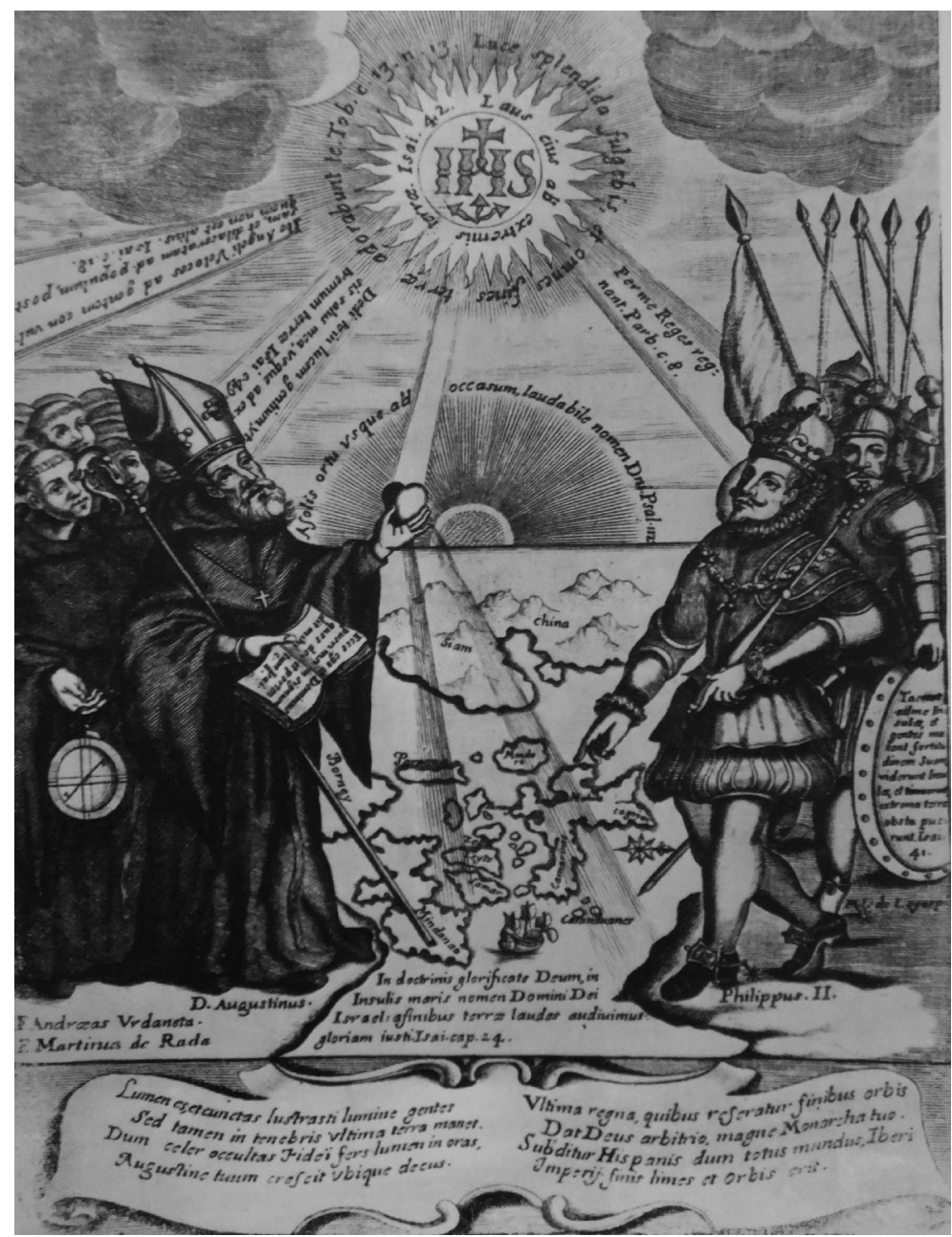


Fernando Ciaramitaro. Doctor en Historia, Universidad de Catania, Italia. Licenciado en Ciencias Políticas, Universidad de Palermo, Italia. Profesor en la Universidad Autónoma de la Ciudad de México e investigador visitante en El Colegio de México. Ha dado cursos en licenciaturas y posgrados y ha sido profesor visitante en algunos centros académicos, europeos y americanos (Casa de Velázquez, Instituto Mora, Universidad Iberoamericana, Pontificia Universidad Católica del Perú, entre otros). Líneas de investigación: sistemas imperiales, Inquisición, monarquía católica, emigración, entre otras. Publicaciones recientes: con José de la Puente Brunke, Extranjeros, naturales y fronteras en la América ibérica y Europa (1492-1830), México-España (2017); con Marcela Ferrari, A través de otros cristales. Viejos y nuevos problemas de la historia politica de Iberoamérica, México-Argentina (2015); Italiani tra Spagna e Nuovo Mondo. Singoli, famiglie e coloni di emigranti (secoli XV-XVIII), Italia (2012).

Recepción: 17 de abril de 2018.

Aprobación: 30 de junio de 2018. 
